\title{
Unipolar versus bipolar hemiarthroplasty for displaced femoral neck fractures: a systematic review and meta-analysis of randomized controlled trials
}

\author{
Zhiwei $\mathrm{Jia}^{1+}$, Fan Ding ${ }^{2 \dagger}$, Yaohong $\mathrm{Wu}^{1+}$, Wei $\mathrm{Li}^{1}$, Haifeng $\mathrm{Li}^{1}$, Deli Wang ${ }^{1}$, Qing $\mathrm{He}^{1 *}$ and Dike Ruan ${ }^{1 *}$
}

\begin{abstract}
Background: Whether bipolar hemiarthroplasty $(\mathrm{BH})$ for displaced femoral neck fractures has benefit over unipolar hemiarthroplasty $(\mathrm{UH})$ remains controversial. We conducted a systematic review and meta-analysis of randomized controlled trials (RCTs) to evaluate the relative effects between $\mathrm{BH}$ and $\mathrm{UH}$.

Methods: A systematic literature search (up to April, 2014) was conducted to include RCTs comparing BH with UH for displaced femoral neck fractures. Two authors independently assessed methodological quality of the included studies and extracted data. Surgical information and postoperative outcomes were analyzed.

Results: A total of 10 RCTs including 1,190 patients were indentified. Our results demonstrated that BH was associated with similar or better outcomes in hip function, hip pain, and quality of life while with a higher cost compared with $\mathrm{UH}$. Moreover, there were no significant differences between $\mathrm{BH}$ and $\mathrm{UH}$ with regard to operation time, blood loss, blood transfusion, hospital stay, mortality, reoperation, dislocation, and complications. BH could significantly decrease the incidence of acetabular erosion at 1 year follow-up compared with UH (RR $=0.24,95 \%$ confidence interval $(\mathrm{Cl})=0.06$ to $0.89, P=0.03)$, but no significant difference was observed at 4 months, 2 years, and 4 years follow-ups.
\end{abstract}

Conclusions: Based on the current evidence, $\mathrm{BH}$ is not superior to $\mathrm{UH}$ in terms of surgical information and postoperative results. Despite similar or better clinical outcomes compared with $\mathrm{UH}$, BH with a higher cost could not decrease long-term acetabular erosion rate.

Keywords: Femoral neck fractures, Arthroplasty, Hemiarthroplasty, Randomized controlled trials, Systematic review, Meta-analysis

\section{Introduction}

Femoral neck fracture is a common fracture in senior patients, which can decrease mobility and increase mortality [1]. There are many options for these fractures including internal fixation, hemiarthroplasty, and total hip arthroplasty [2]. Among these procedures, hemiarthroplasty has become the most preferred treatment option for surgeons according to the surveys [1-3]. There are two types of options, including unipolar hemiarthroplasty (UH) and

\footnotetext{
* Correspondence: heqingngh@163.com; ruandikengh@163.com

${ }^{\dagger}$ Equal contributors

'Department of Orthopaedics, Navy General Hospital, Beijing, China

Full list of author information is available at the end of the article
}

bipolar hemiarthroplasty $(\mathrm{BH})$, when using a hemiarthroplasty. In comparison to $\mathrm{UH}, \mathrm{BH}$ has an additional inner bearing between the stem and the endoprosthetic head component. In theory, this design would decrease acetabular erosion, decrease protrusion, and decrease dislocation, as well as maintain joint stability and improve hip function $[4,5]$. However, whether $\mathrm{UH}$ or $\mathrm{BH}$ is preferable for the patient population remains uncertain [6-13].

Although several randomized controlled trials (RCTs) on this topic have been published, these studies showed inconclusive and controversial results [14-23]. The previous systematic reviews demonstrated that further well-designed RCTs were needed to draw a definitive conclusion, 
indicating the scientific evidence was still insufficient $[24,25]$. However, many RCTs have been published $[14,18,19,21,23,26]$, since the latest meta-analysis conducted in 2010 [25]. The need remains for strong evidence including the recent RCTs to make a more precise estimation [27]. Therefore, the objective of this meta-analysis was to include all available RCTs and to evaluate the relative effects between $\mathrm{UH}$ and $\mathrm{BH}$ for displaced femoral neck fractures.

\section{Materials and methods}

This study was performed and reported following the Preferred Reporting Items for Systematic Reviews and Meta-Analyses (PRISMA) statement [28]. This study was approved by the ethical review committee of Navy General Hospital and Wuhan Pu'Ai Hospital.

\section{Search strategy}

A comprehensive search (up to April, 2014) without restriction on language was independently conducted by two reviews (ZJ and FD) through the databases of Pubmed, Embase, and Cochrane Library. The MeSH terms (hip fractures, femoral neck fractures, arthroplasty, hemiarthroplasty, hip prosthesis) and multiple keywords (unipolar, bipolar, arthroplasty, hemiarthroplasty, replacement, prosthesis, fractur*) were used to ensure inclusion of all possible studies. These terms were connected by the Boolean operators "AND" and "OR". Additionally, the reference lists of included articles and relevant reviews were also examined for potential studies.

\section{Inclusion and exclusion criteria}

The eligible articles should meet the following inclusion criteria: (1) RCTs comparing UH with BH; (2) patients with displaced femoral neck fractures; (3) at least one of the following main clinical outcomes: surgical information and postoperative outcomes. Studies were excluded if they had any of the following characteristics: (1) reviews, abstracts, letters, or meeting proceedings; (2) patients with immature skeleton, delayed union, nonunion, previous surgery, or pathological fractures; (3) duplicate reports of an earlier trial or no interest outcomes reported.

\section{Data extraction}

Two reviewers (ZJ and FD) independently extracted the data from all eligible RCTs with the use of a standardized data recording form. Disagreements were resolved by discussion, a third review (YW) was consulted for the final decision when necessary. The data of interest included the following categories: (1) study characteristics such as year of publication, sample size, age, gender, and follow-up duration; (2) surgical information including operation time, blood loss, blood transfusion, and hospital stay; (3) primary outcomes comprising functional scores, pain, range of motion (ROM), 6-min walk, quality of life and cost (4) secondary outcomes including mortality, reoperation, dislocation, complications, and acetabular erosion. In addition, complications were sorted into four categories, including implant-related complications (periprosthetic fractures, prosthesis loosening, dislocation, etc.), cardiovascular and cerebrovascular complications (cardiac arrest, myocardial infarction, acute cardiac arrhythmia, cerebrovascular accidents, pulmonary embolism, deep venous thrombosis, etc.), local complications (wound infection, wound hematoma, incision rupture, heterotopic ossification, etc.), and general complications (pneumonia, urinary tract infection, bedsore, gastrointestinal bleed, acute renal failure, etc.).

\section{Risk of bias assessment}

Two reviewers (ZJ and FD) independently assessed each of the included study. Disagreements were resolved by means of discussion, with arbitration by a third reviewer (HL), when differences of opinion remained. The risk of bias of the included studies was evaluated using the bias assessment tool recommended by the Cochrane Handbook for Systematic Reviews of Interventions (version 5.1.0) [29]. For each trial, the risk of bias was categorized as low risk, high risk, or unclear risk. Bias assessment was carried out using RevMan 5.2.10 software (Cochrane Collaboration, UK).

\section{Statistical analysis}

For each included study, mean differences (MD) and confidence intervals (CIs) were calculated for continuous outcomes, while risk ratios (RRs) and 95\% CI were calculated for dichotomous outcomes. Heterogeneity across trials was assessed with use of both the chi-square $\left(\chi^{2}\right)$ test and the $I$-squared $\left(I^{2}\right)$ test. Statistical heterogeneity was considered significant when $P<0.10$ for the $\chi^{2}$ test or $I^{2}>50 \%$ [30]. A random effects model was used to ensure that these studies represented a random sample of all potentially available studies [31]. Subgroup analysis was carried out according to specific complication categories and follow-ups. Sensitivity analysis was performed to test the strength and robustness of pooled results by sequential omission of individual studies. Publication bias was assessed using a funnel plot of the most frequently reported outcome. All reported $P$ values were two-sided, and $P<0.05$ was regarded as statistically significant. Statistical analyses were conducted by RevMan 5.2.10 software (Cochrane Collaboration, UK).

\section{Results}

\section{Literature search}

The flow diagram of study selection is shown in Figure 1. A total of 10 RCTs comparing $\mathrm{UH}$ with $\mathrm{BH}$ for displaced femoral neck fractures were included in the present 


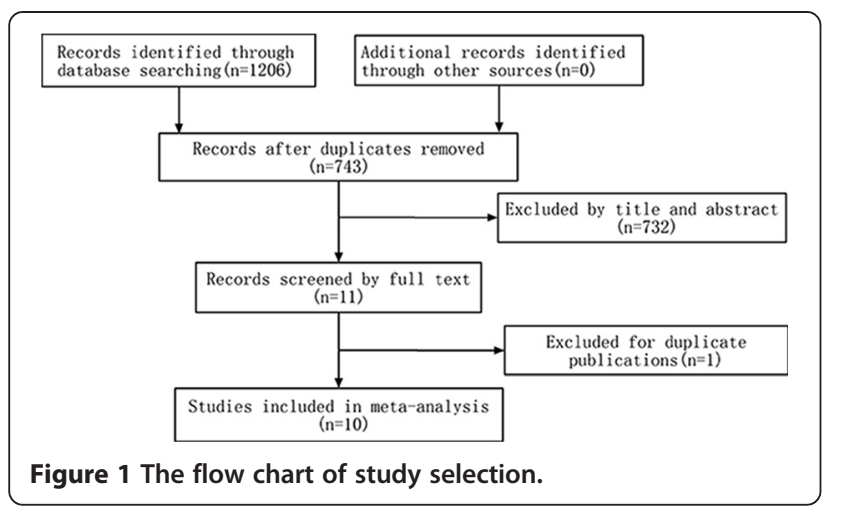

meta-analysis. These studies were from America, Australia, United Kingdom, Sweden, Egypt, Nepal, and India. All selected studies were published in English between 1995 and 2013. The sample size of the RCTs ranged from 40 to 261 . A total of 1,190 patients involving 597 patients for $\mathrm{BH}$ and 593 patients for $\mathrm{UH}$ were identified. Table 1 summarizes the study characteristics of the included studies.

\section{Risk of bias assessment}

The risk of bias of the included studies is illustrated in Figure 2. Seven studies described adequate methods of random sequence generation [15-19,22,23], while the other three trials did not mention the methods of randomization [14,20,21]. Allocation concealment was well described in two trials $[16,18]$ and was unclearly noted in the other eight studies [14,15,17,19-23]. Owing to the nature of the surgical trials, it was impossible to perform blinding of participants. However, patients were blinded to the type of prosthesis in three studies $[16,22,23]$. Additionally, four studies reported that outcome assessors were blinded $[16,17,19,23]$. Therefore the methodological quality of the included studies was low risk of bias.

\section{Surgical information}

The summary of surgical information included operation time, blood loss, blood transfusion, and hospital stay. Due to standard deviation (SD) values of these outcomes were not shown, the meta-analysis could not be performed and a descriptive systematic review was conducted instead. Operation time was evaluated in three studies $[16,18,20]$ and was shown no statistical difference between $\mathrm{BH}$ and $\mathrm{UH}$. Regarding to blood loss revealed in four studies $[16,18,20,22]$, there were no significances observed between the two groups in these studies. Only one study reported blood transfusion and showed that the proportion of blood transfusion was not obviously different [22]. Hospital stay was available in six studies and all these studies demonstrated no significant difference between $\mathrm{UH}$ and $\mathrm{BH}[15-17,20,22,23]$.

\section{Primary outcomes}

\section{Functional scores}

The summary of functional outcomes is listed in Table 2. A total of nine studies assessed the hip function using functional scores [14-19,21-23]. Only one study revealed significant improvement in the $\mathrm{BH}$ group when compared with the UH group [14], while no significance was found in the other eight studies [15-19,21-23]. Various functional scores were used to assess hip function in the included studies, but only Harris hip score (HHS) was adopted in multiple studies $[14,15,17-19,21,23]$. Only two of them $[21,23]$ reported the HSS as mean value and standard deviation, so they were included in the meta-analysis. The pooled results with no heterogeneity $\left(P=0.80, I^{2}=0 \%\right)$ demonstrated that there was no statistical difference between the two groups $(\mathrm{MD}=-0.51,95 \% \mathrm{CI}=-4.43$ to $3.42, P=0.80)$.

\section{Hip pain}

Seven studies reported hip pain [14,15,18,20-23]. Because the methods of pain assessment were different or standard

Table 1 Study characteristics of the included studies

\begin{tabular}{|c|c|c|c|c|c|c|c|c|c|}
\hline \multirow[t]{2}{*}{ Author } & \multirow[t]{2}{*}{ Country } & \multirow[t]{2}{*}{ Study design } & \multicolumn{2}{|c|}{ Patients } & \multicolumn{2}{|c|}{ Mean age $(y)$} & \multicolumn{2}{|c|}{ Gender (M/F) } & \multirow[t]{2}{*}{ Follow-up (months) } \\
\hline & & & $\mathrm{BH}$ & $\mathrm{UH}$ & $\mathrm{BH}$ & $\mathrm{UH}$ & $\mathrm{BH}$ & UH & \\
\hline Inngul [18] & Sweden & RCT & 60 & 60 & 85.5 & 87.4 & $18 / 42$ & $11 / 49$ & 48 \\
\hline Stoffel [23] & Australia & RCT & 133 & 128 & 82.9 & 81.9 & $89 / 172$ & & 12 \\
\hline Mishra [21] & Nepal & $\mathrm{RCT}$ & 20 & 20 & 67 & & $9 / 11$ & $8 / 12$ & 24 \\
\hline Abdelkhalek [14] & Egypt & $\mathrm{RCT}$ & 25 & 25 & 63.5 & & $16 / 34$ & & $24-72$ \\
\hline Jeffcote [19] & Australia & $\mathrm{RCT}$ & 24 & 27 & 80.1 & 81.4 & $6 / 18$ & $6 / 21$ & 24 \\
\hline Raia [22] & America & RCT & 55 & 60 & 82.4 & 81.8 & $13 / 42$ & $19 / 41$ & 12 \\
\hline Davison [17] & United Kingdom & $\mathrm{RCT}$ & 97 & 90 & 75 & 76 & $25 / 72$ & 19/71 & $24-60$ \\
\hline Cornell [16] & America & RCT & 33 & 15 & 78 & 77.6 & $8 / 25$ & $4 / 11$ & 6 \\
\hline Calder [15] & United Kingdom & $\mathrm{RCT}$ & 118 & 132 & 85 & 85 & $17 / 101$ & $18 / 114$ & 24 \\
\hline Malhotra [20] & India & RCT & 32 & 36 & 65 & 68 & $18 / 14$ & $20 / 16$ & $9-47$ \\
\hline
\end{tabular}

$B H$ bipolar hemiarthroplasty, $U H$ unipolar hemiarthroplasty, $R C T$ randomized controlled trial, $M$ male, $F$ female, $N A$ not available. 


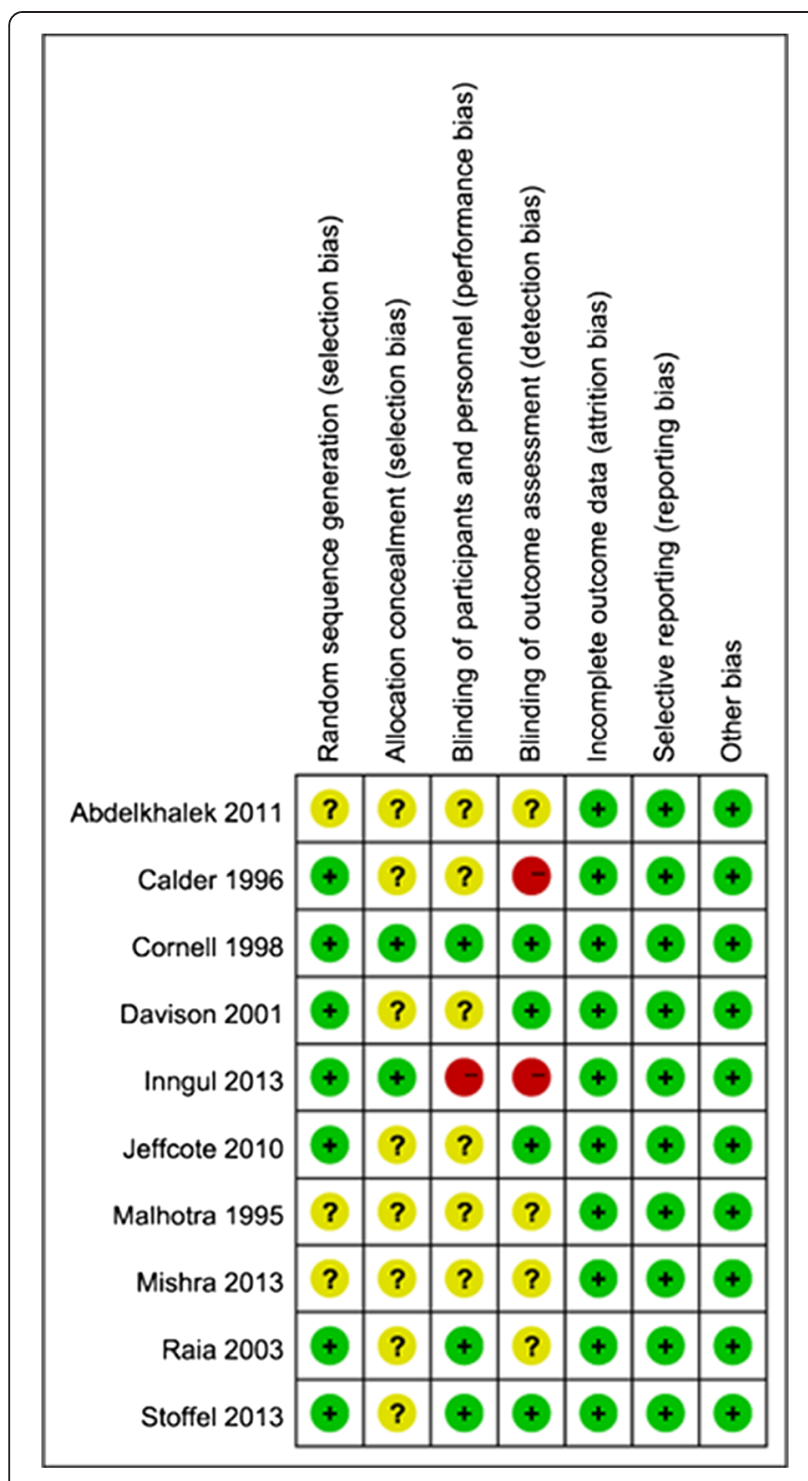

Figure 2 Quality assessment of risk of bias in included studies.

deviation was not available, the pooled analysis could not be performed. Table 2 illustrates a summary of the pain outcomes. Five studies noted that there was no statistical difference between the two groups [15,18,21-23], whereas the other two studies found that $\mathrm{BH}$ was associated with better outcome than that in the UH group according to hip pain $[14,20]$. However, $P$ value was not available in one of them [20].

\section{Range of motion}

ROM of the hip was assessed in six studies $[14,16,18,20,21,23]$, while the results could not be pooled. The findings of the included studies are listed in Table 2. Among them, three studies indicated similar results between $\mathrm{BH}$ and $\mathrm{UH}[18,21,23]$. The other three studies found better ROM in $\mathrm{BH}$ group while the $P$ values were not provided $[14,16,20]$.

\section{Six-minute walk}

Three studies evaluated 6-min walk test $[16,19,23]$ (Table 2). Jeffcote et al. [19] revealed that BH was associated with a statistical improvement at 3 months but not at 12 and 24 months, and Cornell et al. [16] found statistical difference at 6 months. However, no significance was observed in the study by Stoffel et al. [23] during a 1-year follow-up.

\section{Quality of life}

Two studies reported the data of quality of life using SF-36 [22] and EQ-5D [18] (Table 2). Raia et al. [22] conducted a study with a 1-year follow-up and revealed that there was no statistical significance in quality of life according to SF-36 scores between groups. However, Inngul et al. [18] found that EQ-5D was generally higher in the $\mathrm{BH}$ group at the follow-ups with a significant difference at 48 months [18].

\section{Cost}

Two trials assessed the cost of prosthesis [16,23]. All these trials found that the bipolar unipolar implants are more expensive than the unipolar implants $[16,23]$.

\section{Secondary outcomes Mortality}

All included studies reported postoperative mortality. However, it could not be extracted in three studies for the number of death was not available for each group $[17,18,23]$. The pooled analysis of the other seven studies including 622 patients [14-16,19-22] showed that there was no significant difference comparing $\mathrm{BH}$ with $\mathrm{UH}$ $(\mathrm{RR}=0.92,95 \% \mathrm{CI}=0.59$ to $1.44, P=0.71)$. No significant heterogeneity was found $\left(P=0.63, I^{2}=0 \%\right)$.

\section{Reoperation}

Reoperation was evaluated in all the included studies [14-23]. There was no evidence of significant heterogeneity $\left(I^{2}=27 \%, P=0.22\right)$ across the studies. The pooled results showed that no statistical difference was observed between groups $(\mathrm{RR}=0.98,95 \% \mathrm{CI}=0.42$ to $2.27, P=0.95)$.

\section{Dislocation}

All the included studies assessed prosthesis dislocation, whereas one of these studies provided the overall dislocation from both groups and did not report the number in each group [21]. Therefore, the other nine studies with 1,150 patients [14-20,22,23] was pooled to analysis and showed that no evidence of significant difference between the two groups $(\mathrm{RR}=0.76,95 \% \mathrm{CI}=0.30$ to 1.93 , $P=0.57 ; I^{2}=0 \%, P=0.99$ ). 
Table 2 Summary of postoperative clinical outcomes

\begin{tabular}{|c|c|c|c|c|c|}
\hline \multirow[t]{2}{*}{ Study } & \multicolumn{3}{|l|}{ Hip functionality } & \multirow[t]{2}{*}{ Hip pain } & \multirow[t]{2}{*}{ Quality of life } \\
\hline & Functional scores & Six-minute walk & ROM & & \\
\hline Inngul [18] & Similar & NA & Similar & Similar & Better \\
\hline Stoffel [23] & Similar & Similar & Similar & Similar & NA \\
\hline Mishra [21] & Similar & NA & Similar & Similar & NA \\
\hline Abdelkhalek [14] & Better & NA & Better* & Better & NA \\
\hline Jeffcote [19] & Similar & Similar & NA & NA & NA \\
\hline Raia [22] & Similar & NA & NA & Similar & Similar \\
\hline Davison [17] & Similar & NA & NA & NA & NA \\
\hline Cornell [16] & Similar & Better & Better* & NA & NA \\
\hline Calder [15] & Similar & NA & NA & Similar & NA \\
\hline Malhotra [20] & NA & NA & Better* & Better* & NA \\
\hline
\end{tabular}

Better better outcome with statistical difference in bipolar hemiarthroplasty group, Similar similar result with no significance between groups, $R O M$ range of motion, NA not available.

${ }^{*} P$ value is not available.

\section{Complications}

Complications were provided in all the included studies. Two of them did not report the exact number of complications in each group [21,22]. The pooled analysis was conducted in the other eight studies [14-20,23] and demonstrated that there was no statistical difference between the two groups in implant-related complications $\left(\mathrm{RR}=0.84,95 \% \mathrm{CI}=0.39\right.$ to $1.81, P=0.66 ; I^{2}=0 \%$, $P=0.55)$, cardiovascular and cerebrovascular complications $(\mathrm{RR}=1.33,95 \% \mathrm{CI}=0.63$ to $2.81, P=0.45$; $\left.I^{2}=0 \%, P=0.66\right)$, local complications $(\mathrm{RR}=1.53,95 \%$ $\mathrm{CI}=0.71$ to $\left.3.33, P=0.28 ; I^{2}=0 \%, P=0.68\right)$, and general complications $(\mathrm{RR}=0.65,95 \% \mathrm{CI}=0.28$ to 1.49 , $\left.P=0.31 ; I^{2}=0 \%, P=0.34\right)$.

\section{Acetabular erosion}

Six studies evaluated acetabular erosion [14,15,17,18,20,21], while the data was not available in one of these studies [21]. The other five studies were conducted for the pooled analysis $[14,15,17,18,20]$. Actetabular erosion in the $\mathrm{BH}$ group was significantly less than that in the UH group at 1 year follow-up $(\mathrm{RR}=0.24,95 \% \mathrm{CI}=0.06$ to 0.89 , $P=0.03)$, whereas no significant difference was detected between the two groups at postoperative 4 months $(\mathrm{RR}=$ $0.35,95 \% \mathrm{CI}=0.10$ to $1.21, P=0.10)$, at 2 years $(\mathrm{RR}=0.46$, $95 \% \mathrm{CI}=0.20$ to $1.10, P=0.08)$, and at 4 years $(\mathrm{RR}=0.48$, $95 \% \mathrm{CI}=0.20$ to $1.19, P=0.12$ ) (Figure 3 ).

\section{Publication bias and sensitivity analysis}

A funnel plot of the studies reported reoperation was performed. It was illustrated that all studies were distributed evenly about the vertical, indicating minimal evidence of publication bias. Sensitivity analysis was conducted by omission of any individual study while no significant difference was observed in the pooled results.

\section{Discussion}

Hemiarthroplasty, as an effective technique for displaced femoral neck fractures, could help early ambulation and satisfied function recovery and is increasingly performed by the surgeons [1-3]. However, controversy has persisted for a long time regarding the use of bipolar versus unipolar prosthesis. This study suggests that (1) $\mathrm{BH}$ is associated with similar or better improvement in hip functionality, hip pain, and quality of life compared with $\mathrm{UH}$ while with a higher cost and that (2) there are no significant differences between $\mathrm{BH}$ and $\mathrm{UH}$ with regard to operation time, blood loss, blood transfusion, hospital stay, mortality, reoperation, dislocation, and complications, and that (3) $\mathrm{BH}$ could not decrease acetabular erosion rate in the long term.

Compared with UH, bipolar prosthesis with an additional inner articulation has the theoretical advantages of less acetabular erosion and less dislocation [4,5]. This study demonstrates that the incidence of acetabular erosion in $\mathrm{BH}$ is less than that in the $\mathrm{UH}$ group at the follow-ups (Figure 3). These findings are consistent with the previous studies $[6,13]$. However, statistical difference was only noted at 1 year follow-up and the acetabular erosion rate increased at the later follow-ups with no significance observed (Figure 3 ). This may be because the bipolar articulation loses mobility with time and functions as a UH [18,26,32-35]. In addition, it should be recognized that this result should be interpreted with caution until confirmed by future studies, because the number of the pooled studies is small and the studies are of small sample size. Regarding to dislocation, it is not proved to be less comparing $\mathrm{BH}$ with $\mathrm{UH}$ in this study. Other studies have also failed to find this benefit $[3,36,37]$. However, the close reduction of bipolar head is more difficult than the unipolar prosthesis, and $\mathrm{BH}$ 


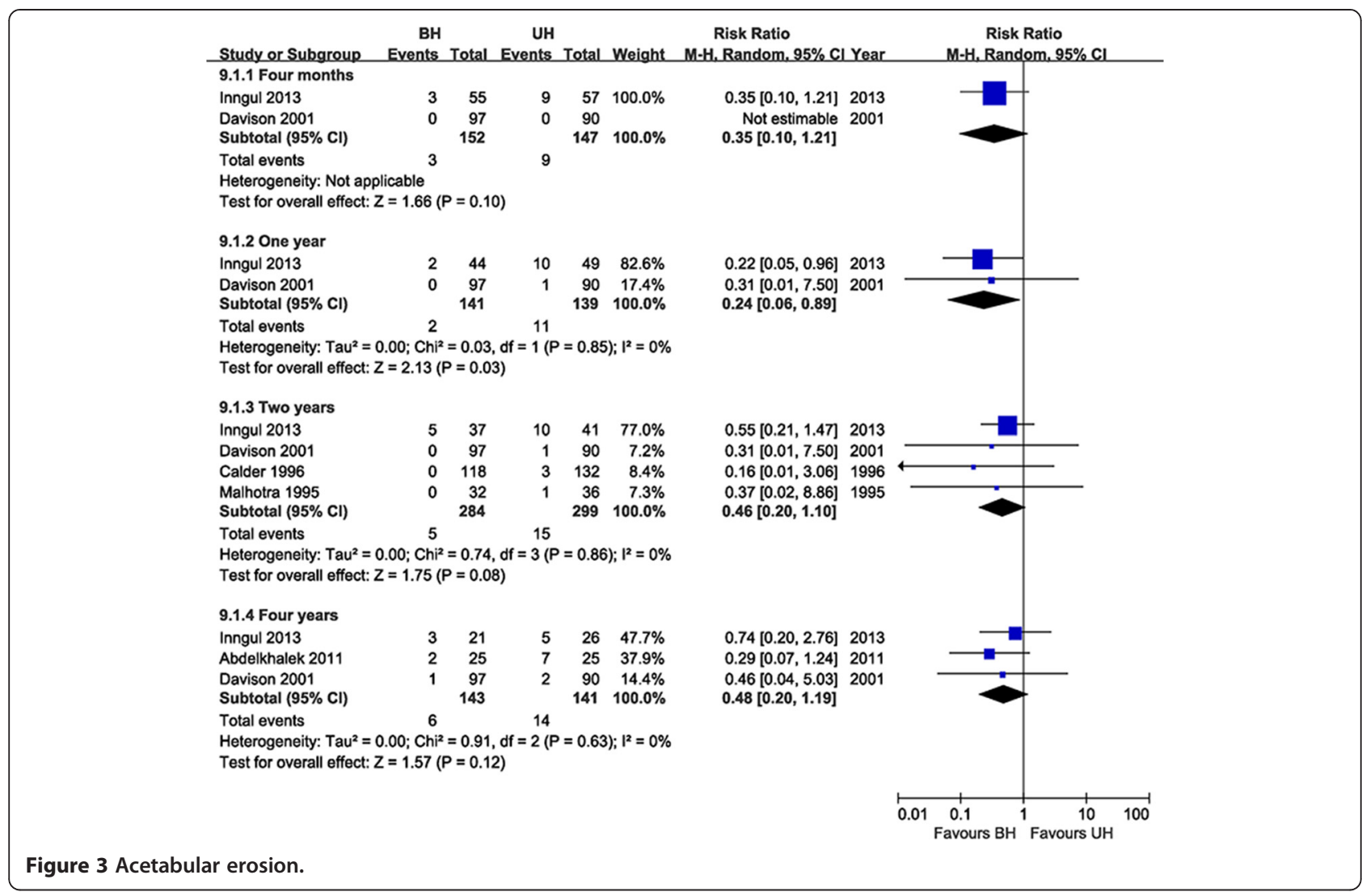

typically requires open reduction [38,39]. Moreover, BH could not increase the risk of operation in terms of surgical and postoperative results, including operation time, blood loss, blood transfusion, hospital stay, mortality, reoperation, dislocation, and complications. It may be demonstrated that $\mathrm{BH}$ is an alternative treatment as safe as $\mathrm{UH}$.

It is also hypothesized that $\mathrm{BH}$ with lower acetabular erosion rate will produce a less painful arthroplasty and improve hip function and quality of life [4,5]. However, this meta-analysis failed to find the statistical difference in HSS score between BH and UH. Other hip functional scores, hip pain, and quality of life according to SF-36 and EQ-5D scores found inconsistent results (similar or better). It may be demonstrated that $\mathrm{BH}$ with a higher cost can achieve no less outcomes, so further studies are needed to perform the cost-effective analysis of BH versus $\mathrm{UH}$. However, it should be recognized that these results were from the qualitative descriptive analysis of the available studies, not the meta-analysis, due to the heterogeneity among the studies. Therefore, more RCTs with the same outcome assessment scores are suggested and may help to get a more reliable conclusion.

The latest systematic review on this topic was published in 2010 and demonstrated that there was no significant difference in clinical outcomes between BU and UH [25]. However, there were several limitations in that study. It included both RCTs and quasi-RCTs, indicating a lower level of evidence of that study. Moreover, although seven studies were included in that study, only five studies were used for analysis, because two studies were conference abstracts without sufficient data. Therefore, there are several strengths in this meta-analysis. Firstly, more strict inclusion criteria were conducted. Only RCTs were included in this study, so the reliability of the results was ensured. Secondly, more RCTs published in recent years were included in this study, making the evidence much stronger. Thirdly, complications were further sorted. The potential bias risk from pooling all complications was decreased.

However, this meta-analysis also has several potential limitations. Firstly, publication bias which is common to all meta-analysis may be still unavoidable in this study. Secondly, various prostheses used in the included studies may induce related bias, whereas a subgroup analysis according to prosthesis type was not conducted due to insufficient data. Thirdly, different outcome measures were reported in the included studies, so a meta-analysis to statically strengthen the evidence could not be performed. Instead, a descriptive systematic review was conducted in these results. 


\section{Conclusions}

This systematic review and meta-analysis suggest that $\mathrm{BH}$ for displaced femoral neck fractures could not have benefit over $\mathrm{UH}$ in terms of surgical information and postoperative results, including operation time, blood loss, blood transfusion, hospital stay, mortality, reoperation, dislocation, and complications. $\mathrm{BH}$ may achieve similar or better outcomes compared with UH with respect to clinical outcomes, including hip functionality, hip pain, and quality of life. However, $\mathrm{BH}$ is associated with higher cost and could not decrease the incidence of acetabular erosion in the long term.

\section{Competing interests}

The authors declare that they have no competing interests.

\section{Authors' contributions}

DR and QH conceived and designed the study. ZJ, FD, and YW performed the study. WL, HL, and DW analyzed the data. ZJ, FD, and YW wrote the manuscript. All authors read and approved the final manuscript.

\section{Acknowledgements}

We would like to thank Dr. Jianhong Wu for his critical reading and modification of the manuscript.

\section{Author details}

${ }^{1}$ Department of Orthopaedics, Navy General Hospital, Beijing, China. ²Department of Orthopaedics, Wuhan Pu'Ai Hospital, Tongji Medical College, Huazhong University of Science and Technology, Wuhan, China.

Received: 16 September 2014 Accepted: 14 January 2015

Published online: 24 January 2015

\section{References}

1. Bhandari M, Devereaux PJ, Tornetta 3rd P, Swiontkowski MF, Berry DJ, Haidukewych $G$, et al. Operative management of displaced femoral neck fractures in elderly patients. An international survey. J Bone Joint Surg Am. 2005:87:2122-30

2. Iorio R, Schwartz B, Macaulay W, Teeney SM, Healy WL, York S. Surgical treatment of displaced femoral neck fractures in the elderly: a survey of the American Association of Hip and Knee Surgeons. J Arthroplasty. 2006:21:1124-33.

3. Crossman PT, Khan RJ, MacDowell A, Gardner AC, Reddy NS, Keene GS A survey of the treatment of displaced intracapsular femoral neck fractures in the UK. Injury. 2002;33:383-6.

4. Bhattacharyya T, Koval KJ. Unipolar versus bipolar hemiarthroplasty for femoral neck fractures: is there a difference? J Orthop Trauma. 2009;23:426-7

5. Gilbert MS, Capozzi J. Unipolar or bipolar prosthesis for the displaced intracapsular hip fracture? An unanswered question. Clin Orthop Relat Res. 1998:353:81-5

6. Lestrange NR. Bipolar arthroplasty for 496 hip fractures. Clin Orthop Relat Res. 1990;251:7-19.

7. Wathne RA, Koval KJ, Aharonoff GB, Zuckerman JD, Jones DA. Modular unipolar versus bipolar prosthesis: a prospective evaluation of functional outcome after femoral neck fracture. J Orthop Trauma. 1995;9:298-302.

8. Kenzora JE, Magaziner J, Hudson J, Hebel JR, Young Y, Hawkes W, et al. Outcome after hemiarthroplasty for femoral neck fractures in the elderly. Clin Orthop Relat Res. 1998:348:51-8.

9. Lin CC, Huang SC, Ou YK, Liu YC, Tsai CM, Chan HH, et al. Survival of patients aged over 80 years after Austin-Moore hemiarthroplasty and bipolar hemiarthroplasty for femoral neck fractures. Asian J Surg. 2012;35:62-6.

10. Enocson A, Hedbeck CJ, Tornkvist H, Tidermark J, Lapidus L. Unipolar versus bipolar Exeter hip hemiarthroplasty: a prospective cohort study on 830 consecutive hips in patients with femoral neck fractures. Int Orthop. 2012:36:711-7.
11. Ong BC, Maurer SG, Aharonoff GB, Zuckerman JD, Koval KJ. Unipolar versus bipolar hemiarthroplasty: functional outcome after femoral neck fracture at a minimum of thirty-six months of follow-up. J Orthop Trauma. 2002;16:317-22.

12. Sabnis B, Brenkel IJ. Unipolar versus bipolar uncemented hemiarthroplasty for elderly patients with displaced intracapsular femoral neck fractures. J Orthop Surg (Hong Kong). 2011;19:8-12.

13. Leonardsson O, Karrholm J, Akesson K, Garellick G, Rogmark C. Higher risk of reoperation for bipolar and uncemented hemiarthroplasty. Acta Orthop. 2012;83:459-66

14. Abdelkhalek M, Abdelwahab M, Ali AM. Bipolar versus fixed-head hip arthroplasty for femoral neck fractures in elderly patients. Strategies Trauma Limb Reconstr. 2011;6:1-6.

15. Calder SJ, Anderson GH, Jagger C, Harper WM, Gregg PJ. Unipolar or bipolar prosthesis for displaced intracapsular hip fracture in octogenarians: a randomised prospective study. J Bone Joint Surg (Br). 1996;78:391-4

16. Cornell CN, Levine D, O'Doherty J, Lyden J. Unipolar versus bipolar hemiarthroplasty for the treatment of femoral neck fractures in the elderly. Clin Orthop Relat Res. 1998;348:67-71.

17. Davison JN, Calder SJ, Anderson GH, Ward G, Jagger C, Harper WM, et al. Treatment for displaced intracapsular fracture of the proximal femur. A prospective, randomised trial in patients aged 65 to 79 years. J Bone Joint Surg (Br). 2001;83:206-12

18. Inngul C, Hedbeck CJ, Blomfeldt R, Lapidus G, Ponzer S, Enocson A. Unipolar hemiarthroplasty versus bipolar hemiarthroplasty in patients with displaced femoral neck fractures. A four-year follow-up of a randomised controlled trial. Int Orthop. 2013;37:2457-64.

19. Jeffcote B, Li MG, Barnet-Moorcroft A, Wood D, Nivbrant B. Roentgen stereophotogrammetric analysis and clinical assessment of unipolar versus bipolar hemiarthroplasty for subcapital femur fracture: a randomized prospective study. ANZ J Surg. 2010;80:242-6.

20. Malhotra R, Arya R, Bhan S. Bipolar hemiarthroplasty in femoral neck fractures. Arch Orthop Trauma Surg. 1995;114:79-82.

21. Mishra AK, Chalise PK, Shah SB, Adhikari V, Singh RP. Comparative study in surgical outcome of intracapsular fracture neck of femur in active elderly patients treated with hemiarthroplasty with Austin Moore's and bipolar prosthesis. Nepal Med Coll J. 2013:15:81-3.

22. Raia FJ, Chapman CB, Herrera MF, Schweppe MW, Michelsen CB, Rosenwasser MP. Unipolar or bipolar hemiarthroplasty for femoral neck fractures in the elderly? Clin Orthop Relat Res. 2003;414:259-65.

23. Stoffel KK, Nivbrant B, Headford J, Nicholls RL, Yates PJ. Does a bipolar hemiprosthesis offer advantages for elderly patients with neck of femur fracture? A clinical trial with 261 patients. ANZ J Surg 2013:83:249-54

24. Lu-Yao GL, Keller RB, Littenberg B, Wennberg JE. Outcomes after displaced fractures of the femoral neck. A meta-analysis of one hundred and six published reports. J Bone Joint Surg Am. 1994;76:15-25.

25. Parker MJ, Gurusamy KS, Azegami S. Arthroplasties (with and without bone cement) for proximal femoral fractures in adults. Cochrane Database Syst Rev. 2010;6:CD001706.

26. Hedbeck CJ, Blomfeldt R, Lapidus G, Tornkvist H, Ponzer S, Tidermark J. Unipolar hemiarthroplasty versus bipolar hemiarthroplasty in the most elderly patients with displaced femoral neck fractures: a randomised, controlled trial. Int Orthop. 2011;35:1703-11.

27. Evaniew N, Madden K, Bhandari M. Cochrane in CORR ((R)): arthroplasties (with and without bone cement) for proximal femoral fractures in adults. Clin Orthop Relat Res. 2014:472:1367-72.

28. Moher D, Liberati A, Tetzlaff J, Altman DG. Preferred reporting items for systematic reviews and meta-analyses: the PRISMA statement. PLoS Med. 2009;6:e1000097.

29. Higgins JPT, Green S (editors). Cochrane handbook for systematic reviews of interventions version 5.1.0 [updated March 2011]. The Cochrane Collaboration, 2011. Available from http://handbook.cochrane.org

30. Higgins JP, Thompson SG, Deeks JJ, Altman DG. Measuring inconsistency in meta-analyses. BMJ. 2003:327:557-60.

31. DerSimonian R, Laird N. Meta-analysis in clinical trials. Control Clin Trials. 1986;7:177-88.

32. Verberne $\mathrm{GH}$. A femoral head prosthesis with a built-in joint. A radiological study of the movements of the two components. J Bone Joint Surg (Br). 1983;65:544-7 
33. Phillips TW. The Bateman bipolar femoral head replacement. A fluoroscopic study of movement over a four-year period. J Bone Joint Surg (Br). 1987;69:761-4.

34. Chen SC, Badrinath K, Pell LH, Mitchell K. The movements of the components of the Hastings bipolar prosthesis. A radiographic study in 65 patients. J Bone Joint Surg (Br). 1989;71:186-8.

35. Eiskjaer S, Boll K, Gelineck J. Component motion in bipolar cemented hemiarthroplasty. J Orthop Trauma. 1989;3:313-6.

36. Rae PJ, Hodgkinson JP, Meadows TH, Davies DR, Hargadon EJ. Treatment of displaced subcapital fractures with the Charnley-Hastings hemiarthroplasty. J Bone Joint Surg (Br). 1989;71:478-82.

37. Varley J, Parker MJ. Stability of hip hemiarthroplasties. Int Orthop. 2004:28:274-7.

38. Georgiou G, Siapkara A, Dimitrakopoulou A, Provelengios S, Dounis E. Dissociation of bipolar hemiarthroplasty of the hip after dislocation. A report of five different cases and review of literature. Injury. 2006;37:162-8.

39. Sierra RJ, Schleck CD, Cabanela ME. Dislocation of bipolar hemiarthroplasty: rate, contributing factors, and outcome. Clin Orthop Relat Res. 2006:442:230-8.

\section{Submit your next manuscript to BioMed Central and take full advantage of:}

- Convenient online submission

- Thorough peer review

- No space constraints or color figure charges

- Immediate publication on acceptance

- Inclusion in PubMed, CAS, Scopus and Google Scholar

- Research which is freely available for redistribution 